\title{
Medial Amygdala Arginine Vasopressin Neurons Regulate Innate Aversion to Cat Odors in Male Mice
}

\author{
Wen Han Tong Samira Abdulai-Saiku Ajai Vyas \\ School of Biological Sciences, Nanyang Technological University, Singapore, Singapore
}

\section{Keywords}

Defensive behaviors - Extended amygdala · Innate fear .

Medial amygdala · Nonapeptides · Reproductive behaviors . Vasotocin $\cdot$ Sexual selection

\begin{abstract}
Aversion to environmental cues of predators is an integral part of defensive behaviors in many prey animals. It enhances their survival and probability of future reproduction. At the same time, animals cannot be maximally defended because imperatives of defense usually trade-off with behaviors required for sexual reproduction like display of dominance and production of sexual pheromones. Here, we approach this trade-off through the lens of arginine vasopressin (AVP) neurons within the posterodorsal medial amygdala (MePD) of mice. This neuronal population is known to be involved in sexual behaviors like approach to sexually salient cues. We show that chemogenetic partial ablation of this neuronal population increases aversion to predator odors. Moreover, overexpression of AVP within this population is sufficient to reduce aversion to predator odors. The loss of fear of the predator odor occurs in parallel with increased recruitment of AVP neurons within the MePD. These obser-
\end{abstract}

karger@karger.com

(c) 2020 S. Karger AG, Basel

www.karger.com/nen

Karger" vations suggest that AVP neurons in the medial aspect of the extended amygdala are a proximate locus for the reduction in innate fear during life stages dominated by reproductive efforts.

(c) 2020 S. Karger AG, Basel

\section{Introduction}

Reproduction and defense are 2 primary pursuits for animals. These pursuits are guided by behaviors like sexual investment, aversion to cues of predator presence, and the accompanying changes in their motivational states. Many of these behaviors are innate in the sense that their expression is independent of individual experience. And yet, these innate behaviors are continually modulated by the incipient environment of the animals. The living environment of animals is typically replete with uncertainties [1]. The availability of reproductive opportunities cannot be predicted with precision. Probabilities of exposure to predators are likewise variable. These uncertainties require animals to make continuous calibration of innate behaviors as a function of environmental cues. One of the most crucial adjustments in this regard is to reduce 
defensive behaviors when reproductive opportunities are present [2-7]. Successful reproduction involves behaviors that are not commensurate with maximal defense. In many species, males must produce publicly broadcasted sexual advertisements that can be perceived by both the intended audience of females and the unintended audience of predators. Males must actively pursue females and compete with other male suitors. These behaviors require at least a temporary suspension of defensive behaviors against predators. The trade-off between predation and reproduction has been widely studied in ecology. However, the neural mechanisms that permit such behavioral trade-off to exist through a reciprocal inversion between reproduction and defense remain currently unknown.

The medial amygdala is an essential node within the social brain network inside the vertebrate brain $[8,9]$. It is likely that the medial amygdala plays a vital role in the process of reciprocal interaction between reproductive and defensive behaviors. The medial amygdala receives information about the olfactory environment through converging inputs initiating from main and accessory olfactory systems $[10,11]$. Thus, the medial amygdala has access to environmental variability through chemosensory information about the presence of predators or reproductive opportunities. It projects to brain circuits involved in motivation and to effector modules within the hypothalamus [12-19]. These efferent connections provide a pathway for the medial amygdala to coordinate downstream reproductive or defensive behaviors. Anatomically, the posterior aspect of the medial amygdala exhibits broad functional segregation. The posterodorsal medial amygdala (MePD) is chiefly involved in response to cues of reproductive opportunities, and the posteroventral medial amygdala responds robustly to cues of predator presence [20-25]. Lesion studies also support the essential role of the posterodorsal and posteroventral medial amygdala in reproduction and defense, respectively $[26,27]$. Thus, environmental cues with contrasting behavioral implications are processed in adjacency within the posterior medial amygdala.

Rodent MePD is enriched in neurons that synthesize the nonapeptide arginine vasopressin (AVP) [15, 28-30]. This extrahypothalamic pool of AVP neurons is preferentially found in males and is dependent on androgens [30-33]. The location within MePD, in addition to sexual dimorphism and androgen responsivity, suggests that $\mathrm{MePD}-\mathrm{AVP}+$ neurons are an important component in the mediation of reproductively motivated behaviors. This is supported by the observation that MePD-AVP+ neurons exhibit robust activity when male rodents are ex- posed to the smell of estrus females or after copulation [34-38]. These observations are congruent with experiments in birds, where analogous vasotocin neurons within the medial aspect of the extended amygdala are recruited during behaviors that are shaped by sexual selection [39-42]. For example, territorial behaviors by male birds when expressed in the context of reproduction involve vasotocin neurons, while the same behavior in the context of nonreproductive resource defense does not involve this neuronal population.

Thus, reproductive and defensive behaviors represent a reciprocal trade-off. The medial amygdala, specifically the posterior parts of the medial amygdala, contains 2 subdivisions that are essential for reproductive and defensive behaviors, and it contains neurons (MePD-AVP+) that are responsive to gonadal hormones that initiate and sustain reproductive behaviors.

In this context, our aim here is to delineate the role of MePD-AVP+ neurons in the mediation of innate fear to predator odor. We ask if overexpression of AVP within $\mathrm{MePD}-\mathrm{AVP}+$ neurons increases their recruitment during exposure to predator odor, and if such a manipulation concomitantly reduces fear. We also ask if partial ablation of MePD-AVP+ neurons reduces the recruitment of remaining AVP neurons concomitant to increased fear of predator odors.

\section{Materials and Methods}

\section{Animals}

A transgenic mice line expressing Cre recombinase from AVP promotor was acquired (JAX stock 023530; Jackson Laboratory; background strain C57BL/6J [43]). Heterozygote animals from this line were crossed with wild-type C57BL/6 animals procured from a local vivarium (InVivos, Singapore). Littermates were genotyped after cessation of all imaging and behavioral experiments by sequencing PCR amplification products of genomic DNA obtained from tail snips and primers suggested by the commercial supplier.

All experimental procedures were reviewed and approved by the Institutional Animal Care and Use Committee of the Nanyang Technological University. Only male animals were used in these experiments in view of gender dimorphism inherent in the medial amygdala AVP system. Animals were maintained on a 12-h:12-h day-night cycle with ad libitum access to food and water (lights on at 07:00 h; 4-5 animals/cage).

\section{Viral Vectors}

Adeno-associated viral vectors were used to deliver genes for either diphtheria toxin receptor (DTR) or AVP within the MePD. A freely available viral backbone, pAAV-EF1a-DIO-mCherryWPRE (AddGene), was used. The vector contains EF1a promoter and double inverted loxP elements flanking complementary DNA sequences in inverted orientation and a WPRE element for ex- 
pression optimization. The vector used for AVP overexpression allowed AVP expression from a robust EF1 $\alpha$ promoter after a recombination event dependent on the presence of Cre recombinase (pAAV-EF1a-DIO-AVP-IRES-hrGFP-WPRE). An IRES gene was inserted between AVP (gene ID: NM-016992) and GFP coding sequences to allow co-expression of AVP and GFP upon Cre recombination. The forward and reverse primers for the entire PCR fragment contained Nhel (GCTAGC) and AscI (GGCGCGCC) restriction sites. The resulting PCR amplicon was digested with Nhel and $A s c l$ restriction enzymes and cloned into the pAAV-EF1a-DIO-mCherry backbone between the inverted terminal repeats. The AVP ablation vector, pAAV-EF1a-DIO-DTRIRES-hrGFP-WPRE, was created using the same techniques (gene ID: AK222688.1). This vector allowed expression of DTR in the presence of Cre recombinase. Viral particles were packaged and synthesized by VectorBuilder (Cyagen Biosciences) at a concentration of $>10^{11}$ viral particles/mL. These AAV viral particles expressed cargo when transduced in human embryonic kidney 293T cells expressing Cre recombinase (online suppl. Figure 1; see www.karger.com/doi/10.1159/000508862 for all online suppl. material).

\section{Timeline of Experiments}

Animals were more than 7 weeks old at the start of the experiment. We did not carry out genotyping of littermates at the start of the experiment, expecting a mendelian equivalence between animals with or without Cre recombinase. This ensured that experimenters were blind to the experimental groups until all behavioral and immunohistological imaging experiments were finished. Littermates were randomly assigned to receive 1 of the 2 viral vectors used in the study. Viral vectors were delivered at 7-8 weeks of age through stereotaxic injections targeted at MePD.

Mice were left to recover for 4 weeks before subsequent experiments. For animals infused with a vector containing DTR, 2 doses of diphtheria toxin were administered 2 and 3 weeks after surgery (Sigma-Aldrich D0564; $50 \mu \mathrm{g} / \mathrm{kg}$ body weight i.p., dissolved in buffered saline at $10 \mu \mathrm{g} / \mathrm{mL})[44,45]$.

Aversion to bobcat urine was quantified 4 weeks after stereotaxic injection of viral vectors. Animals were sacrificed $2 \mathrm{~h}$ after exposure to bobcat urine during the aversion assay. Harvested brains were then used to quantify neurons expressing AVP and Fos (an immediate-early gene marker for recent neuronal activity). Tails were harvested during terminal dissection and used for genotyping the animals after data used for statistical analysis had been obtained.

\section{Surgical Methods}

The following coordinates were used to position the infusion at the MePD: anteroposterior: -1.70 , mediolateral: \pm 2.00 , and dorsoventral: -5.00 from bregma [46]. Prior to all stereotaxic surgeries, mice were anesthetized with $2-3 \%$ isoflurane, placed on an isothermal heating pad, and the head was mounted in a stereotaxic frame (Leica Biosystems Vernier Stereotaxic w/Manual Fine Drive Stereotaxic Instrument for Small Animals). Ophthalmic ointment was used to cover the eyes. The scalp was sterilized, and the skull was exposed. Small bilateral holes were drilled into the cranium. Three microliters of AAV viral particles were infused bilaterally into the MePD at an injection rate of $0.3 \mu \mathrm{L} / \mathrm{min}$ and a total volume of $3 \mu \mathrm{L}$ via a 26 -gauge stainless steel cannula. The cannula was lowered to the targeted MePD site and left in place for
1 min before and 2 min after injection to prevent any back pressure from forming during the AAV viral particle infusion. Special care was taken to remove the dura so as not to clog the cannula during the infusion.

Diphtheria toxin was purchased from Sigma-Aldrich (D0564) as lyophilized powder, reconstituted in sterile phosphate-buffered saline (PBS) at $1 \mathrm{mg} / \mathrm{mL}$, and aliquots were stored at $-80^{\circ} \mathrm{C}$. Two weeks after viral delivery, the working stock was prepared freshly by diluting the stored toxin 100 times in sterile PBS to a final concentration of $10 \mu \mathrm{g} / \mathrm{mL}$. The toxin was administered intraperitoneally $(50 \mu \mathrm{g} / \mathrm{kg}$ body weight) to animals assigned to the DTR experiment. The second round of a single dose of the toxin was administered the following week.

\section{Behavioral Measurements}

The experiments were conducted in a rectangular arena $(46 \times$ $9 \mathrm{~cm}$ ), which was divided into 2 opposing and identical sections. Mice were first habituated to the testing arena for 3 consecutive days for 1,200 $\mathrm{s}$ in the absence of bobcat urine (09:00-14:00 h). During the last of the 3 habituations, mice were additionally exposed to a novel odor (vanilla extract, $2 \mathrm{~mL}$; dilution 1:4). The following day, aversion to bobcat urine was quantified by measuring occupancy in the bisect containing $1 \mathrm{~mL}$ of undiluted bobcat urine (100\% pure PredatorPee ${ }^{\circledR}$ bobcat urine from PredatorPee). Bobcat urine was pipetted onto and absorbed by a piece of c-Fold tissue paper. This bobcat odor paper was then clipped on the far end of the rectangular arena. The bobcat odor paper was changed and freshly prepared for each round of testing. After each trial, the arena was thoroughly cleaned with F-10 and 70\% ethanol to prevent lingering odor caused by the mouse's urine and waste products. A 20-min interval was given between trials to ensure all odor has dissipated (trial duration $=1,200 \mathrm{~s}$ ).

\section{Immunohistological Staining}

The product of immediate-early gene $c$ Fos was used as a proxy for recent neuronal activity (Fos). Animals were returned to their home cage and were not disturbed for $2 \mathrm{~h}$ after exposure to bobcat urine during the behavioral assay - this period allowed time for transcription, translation, and intranuclear localization of Fos. Animals were deeply anesthetized with isoflurane. Transcardial perfusion was performed with $50 \mathrm{~mL}$ PBS followed by $50 \mathrm{~mL}$ of $4 \%$ paraformaldehyde dissolved in PBS. Brains were harvested and postfixed in $4 \%$ paraformaldehyde overnight at $4{ }^{\circ} \mathrm{C}$. They were then transferred to $30 \%$ (wt/vol) sucrose for at least $24 \mathrm{~h}$ or until they sank to the bottom. Serial $40-\mu \mathrm{m}$-thick coronal sections through the medial amygdala were collected via a Leica CM1950 cryostat at $-22^{\circ} \mathrm{C}$, and free-floating sections were stored at $-20^{\circ} \mathrm{C}$ in antifreeze solution ( 2 parts PBS, 1 part ethylene glycol, 1 part glycerol). For antibody staining, sections were first washed in $1 \times$ PBS $(3 \times 10 \mathrm{~min})$ before subjected to blocking with PBS containing $5 \%$ ( vol/vol) goat serum overnight at $4{ }^{\circ} \mathrm{C}$. Free-floating brain sections were then incubated in a cocktail of primary antibodies in $0.5 \%$ Triton X-100 and $1 \times$ TBS for $72 \mathrm{~h}$ at $4{ }^{\circ} \mathrm{C}$ : guinea pig antiAVP (T-5048; Peninsula Laboratories, 1:1,500), rabbit anti-Fos (ABE457; Merck Millipore, 1:10,000) followed by washing in $1 \times$ PBS for $6 \times 10 \mathrm{~min}$. Free-floating brain sections were then incubated in a cocktail of secondary antibodies in $0.5 \%$ Triton X-100 and $1 \times$ TBS for $2 \mathrm{~h}$ at room temperature: Alexa Fluor 488 AffiniPure donkey anti-guinea pig (706-545-148; Jackson Immunoresearch Laboratories, 1:1,000), Dylight 549 goat anti-rabbit 


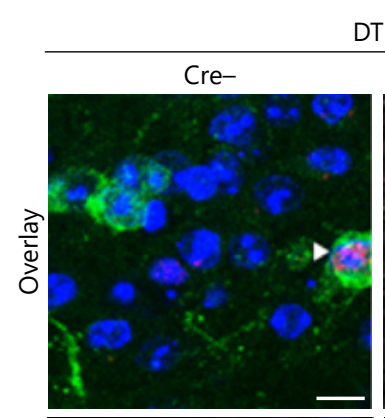

DTR
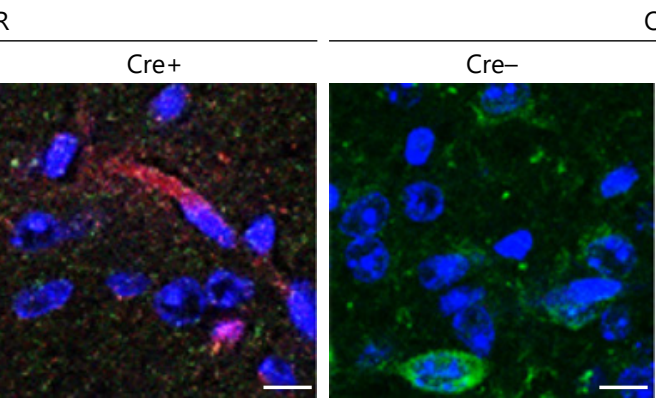

$\mathrm{OE}$
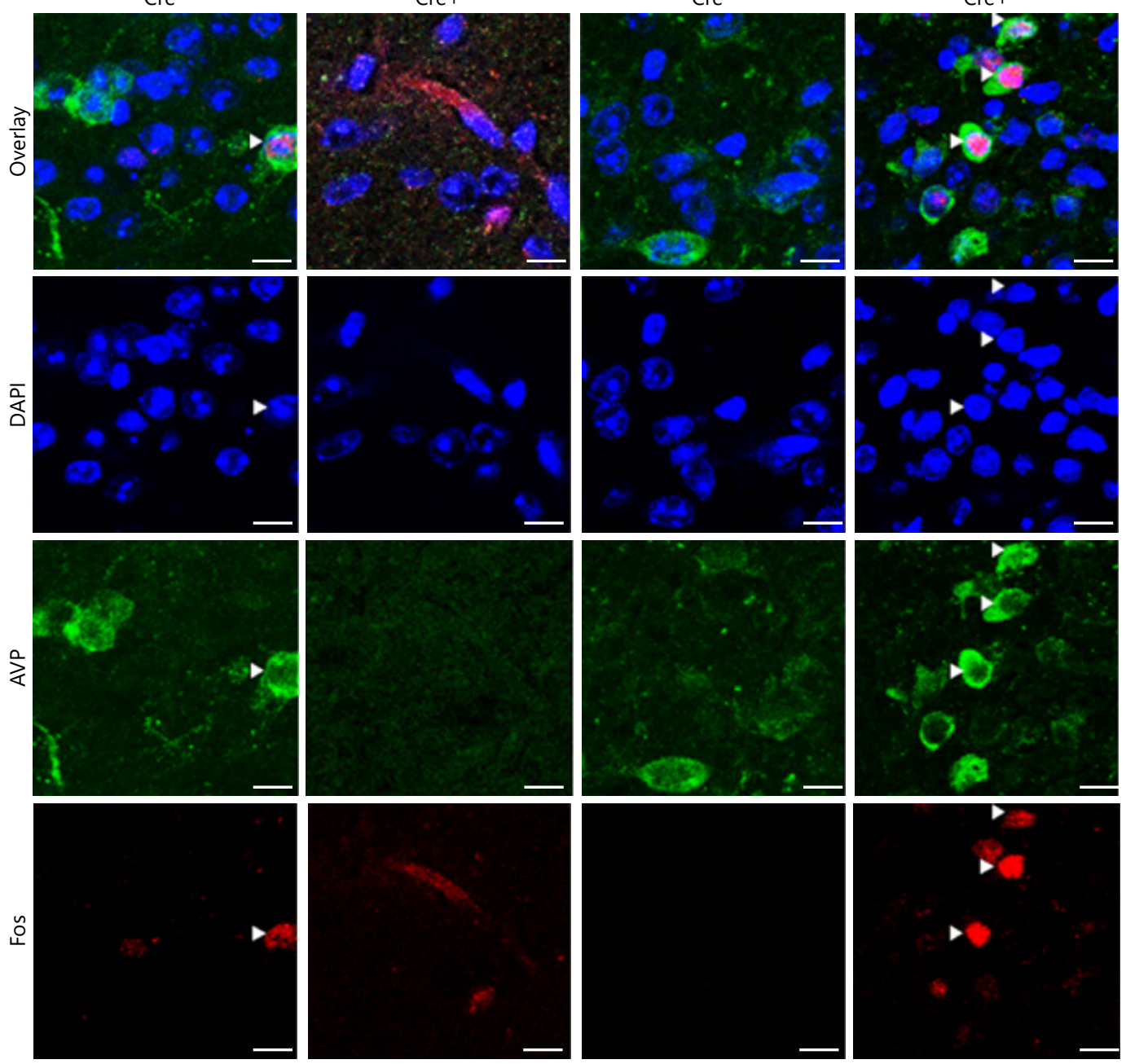

Fig. 1. Representative images showing immunofluorescences for arginine vasopressin (AVP), Fos (a marker for recent neuronal activity), and nuclear boundaries (DAPI). Animals were surgically infused with viral vectors containing cargos of diphtheria toxin

(DI-5149; Vector Laboratories, 1:1,000), followed by washing in $1 \times$ PBS for $6 \times 10 \mathrm{~min}$. Sections were then mounted on Superfrost slides (Fisher Scientific, USA) and completely air-dried. This was followed by mounting with coverslips using Gold Antifade Mountant with DAPI (P36931; Life Technologies).

\section{Imaging}

We centered slides on MePD using the DAPI signal as a guide at low magnification. Three stacks within the MePD were then chosen randomly for the image capture at higher magnification for the analysis. Images were captured with the Carl Zeiss LSM 710 laser scanning confocal microscope using a $\times 40$ objective lens with a $\times 1.2$ digital magnification. Sections were optically sliced at $1-\mu \mathrm{m}$ receptor (DTR) or AVP overexpression (OE) within the posterodorsal medial amygdala. The expression of cargos was dependent on the availability of Cre recombinase in the genome of animals. Examples from Cre- to Cre+ are depicted. Scale bars, $10 \mu \mathrm{m}$.

intervals. All DAPI-positive nuclei were counted $(866 \pm 23$ DAPI+ cells, coefficient of variation $=15 \%$ ). All neurons showing positive immunoreactivity for AVP, or Fos, or colabeled neurons with both AVP and Fos, were counted (Fig. 1). Caution was taken not to duplicate neuron counts across different optical slices. Scores were cumulated per animal across 3 image stacks, leading to total AVP+ (i.e., cells with only AVP+ identities + colabeled neurons), total Fos+ (i.e., cells with only Fos+ identities + colabeled neurons), colabeled neurons with both AVP+ and Fos+, and the total number of DAPI-positive nuclei. Cumulated numbers were then expressed as the percentage of DAPI-positive nuclei and then statistically analyzed. The experimenters remained blind to the experimental treatment groups while scoring. 
Table 1. Effect size and type 1 error probabilities for imaging and behavioral endpoints

\begin{tabular}{|c|c|c|c|c|c|}
\hline \multirow[t]{2}{*}{ Endpoint } & \multirow[t]{2}{*}{ Interaction } & \multicolumn{2}{|c|}{ DTR vector ${ }^{2}$} & \multicolumn{2}{|c|}{ OE vector ${ }^{3}$} \\
\hline & & $p$ value $^{4}$ & Hedges' $g^{5}$ & $p$ value $^{4}$ & Hedges' $g^{5}$ \\
\hline Percent $\mathrm{AVP}+$ in $\mathrm{MePD}$ & $\begin{array}{l}F_{(1,26)}=63.63 \\
p<0.001\end{array}$ & $<0.0001$ & 4.4 & 0.0026 & 1.7 \\
\hline Percent Fos+ in MePD & $\begin{array}{l}F_{(1,26)}=30.79 \\
p<0.001\end{array}$ & 0.0389 & 1.0 & $<0.0001$ & 3.4 \\
\hline Percent colabeled in MePD & $\begin{array}{l}F_{(1,26)}=50.48 \\
p<0.001\end{array}$ & $<0.0001$ & 1.9 & $<0.0001$ & 4.0 \\
\hline Time spent in bobcat bisect & $\begin{array}{l}F_{(1,26)}=7.88 \\
p=0.007\end{array}$ & 0.0527 & 0.8 & 0.0527 & 0.9 \\
\hline
\end{tabular}

\footnotetext{
${ }^{1} F$, df, and $p$ values for interaction obtained during ANOVA for 2 between-subject sources of variance (Cre genotype and viral vector).

${ }^{2}$ Cre $->$ Cre + for all intergroup comparisons when infused with vector containing diphtheria toxin receptor.

${ }^{3} \mathrm{Cre}-<$ Cre+ for all intergroup comparisons when infused with overexpression vector.

${ }^{4}$ Probability of type 1 error for comparison between Cre- and Cre+ littermates.

${ }^{5}$ Standardized effect size. $1 \mathrm{~g}=$ an intergroup difference of $1 \mathrm{SD}$.
}

Analysis and Statistics

Each individual animal was used as a biological replicate. The number of animals is depicted in each of the figures, along with raw values. Statistical analysis was carried out using GraphPad Prism 7.0 software.

All endpoints were tested for normality of the distribution using the Shapiro-Wilk test [47]. Several imaging and behavioral endpoints significantly departed from normality. For consistency, all data were rank transformed before subsequent analysis [48], and normality of the transformed data was reconfirmed. Figures represent both transformed and nontransformed data. Probabilities of type 1 error were consistent regardless of whether rank transformation was used. Outliers were examined using the ROUT method with a maximum false discovery rate set at $1 \%$ [49]. No outliers were found in the rank-transformed data.

A two-way analysis of variance was conducted with genotype (presence or absence of Cre) and vector (experimentally infused with a viral vector containing either floxed DTR or floxed AVP) as between-subject sources of variance. All endpoints exhibited significant interaction between genotype and experimental infusion. We further conducted 2 post hoc comparisons using Fisher's LSD test (animals with or without Cre, infused with viral vector containing DTR, and animals with or without Cre, infused with viral vector containing AVP overexpression, OE). We avoided nonorthogonal omnibus post hoc comparisons to avoid inflation of significant values associated with multiple testing [50]. The $t_{\mathrm{df}}$ values and associated $p$ values for individual comparisons are stated within the Results and in the Figures.

The magnitude of intergroup differences was computed using Hedges' unbiased $g$ (the difference between 2 means divided by the pooled SD for the data) [51]. This is a standardized measure of effect size independent of mean quantities, reported in the Results and in Table 1 along with 95\% CIs. A $g$ of 1 indicates intergroup differences equal to $1 \mathrm{SD}$.

MePD-AVP Neurons Regulate Innate Aversion to Cat Odors

\section{Results}

Briefly, we manipulated those MePD neurons that have an endogenous AVP identity (MePD-AVP+ neurons) using viral vectors containing cargos with Cre-dependent expression. Animals containing a gene for Cre recombinase (Cre+) were compared with corresponding control littermates without Cre (Cre-). We strove to ablate MePD-AVP neurons using a vector containing DTR and overexpressing AVP in this neuronal population with a vector containing AVP gene driven from a robust promoter (OE).

Experimental Manipulation of $M e P D-A V P+$ Neurons

Analysis of variance (ANOVA) was conducted with vector (DTR or OE) and genetic background of recipient animals (Cre+ or Cre-) designated as between-subject sources of variance (Fig. 2). Rank-transformed data were used. ANOVA revealed statistically significant interaction between vectors and Cre genotype $\left(F_{[1,26]}=63.6, p<\right.$ $0.001)$. The interaction accounted for $59 \%$ of the total variance in the design $(\Delta \bar{x} \pm 95 \%$ CI $26.6 \pm 6.9$ ranks). The main effect of vectors was significant $\left(F_{[1,26]}=5.0\right.$, $p=0.034)$. The main effect of Cre genotypes was also significant $\left(F_{[1,26]}=9.6, p=0.005\right)$.

We used 2 comparisons to analyze the effects of DTR and $\mathrm{OE}$ treatments on immunohistologically detected $\mathrm{MePD}-\mathrm{AVP}+$ neurons, comparing $\mathrm{Cre}+$ and Cre- littermates in each instance using Fisher's LSD test. Expres- 


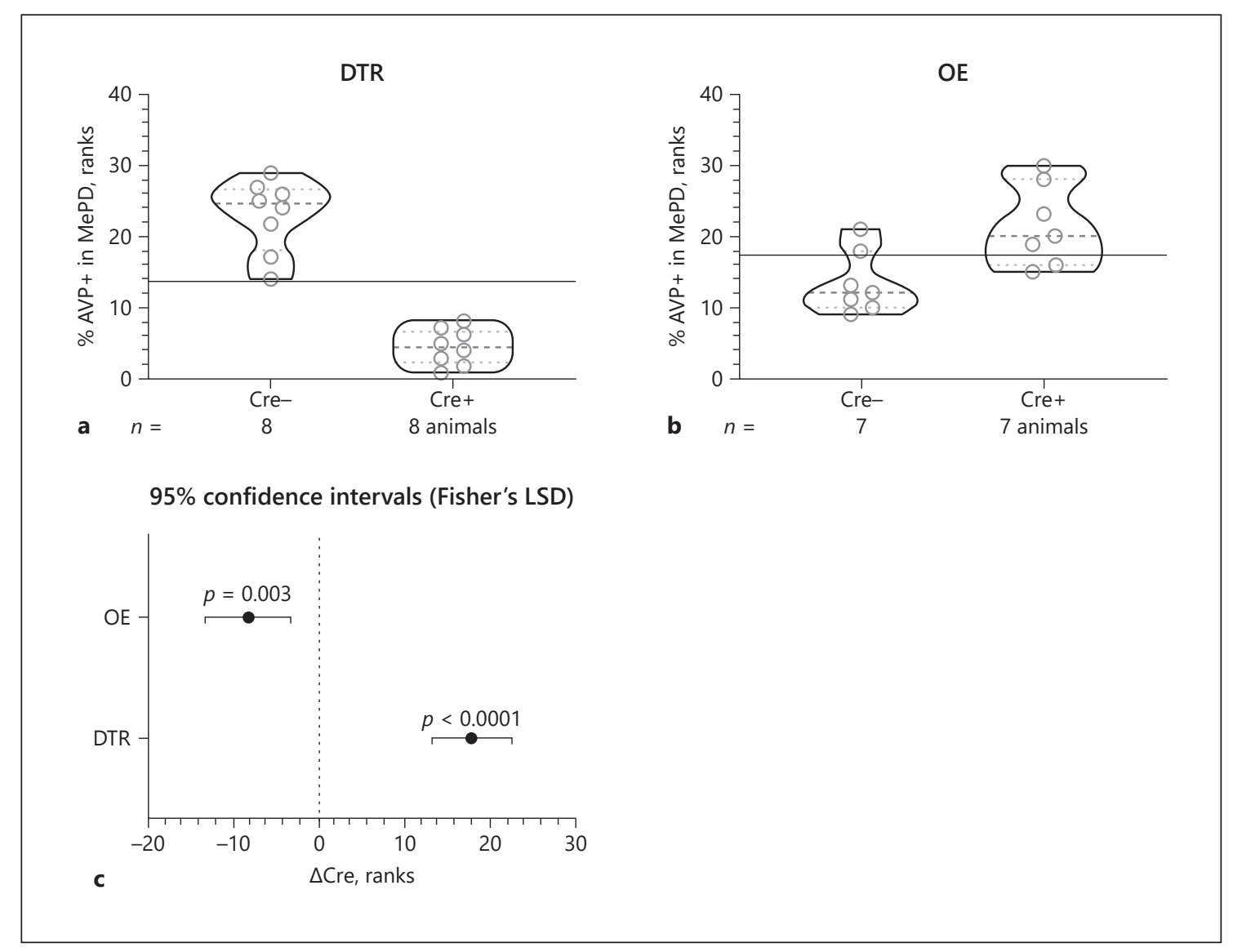

Fig. 2. Effects of experimental manipulations on arginine vasopressin (AVP) neurons within the posterodorsal medial amygdala (MePD) after partial ablation using diphtheria toxin receptor (DTR; a) or overexpression (OE; b). The number of AVP+ neurons relative to total neurons counted is depicted on the ordinates after rank transformation. Violin plots in these panels depict me-

sion of DTR and subsequent administration of diphtheria toxin resulted in a robust ablation of MePD-AVP+ neurons $\left(t_{26}=8.1, p<0.001 ; \Delta \overline{\mathrm{x}}=18.5 \pm 2.3\right.$ ranks). The number of AVP+ neurons in all DTR animals (expressed as a percentage of total cells counted) was lower than the minima of non-DTR controls (Hedges' $g=4.4$ ). In contrast, Cre+ animals receiving OE vector exhibited a substantial increase in immunohistologically revealed $\mathrm{MePD}-\mathrm{AVP}+$ neurons compared to Cre- littermates $\left(t_{26}=3.3, p=0.003 ; \Delta \bar{x}=8.1 \pm 2.4\right.$ ranks). Only 2 of 7 control animals exhibited more neurons with detectable AVP compared to the minima of Cre+ littermates (Hedges' $g=1.7$ ). Thus, DTR caused a partial ablation, and $\mathrm{OE}$ increased the number of MePD-AVP+ neurons that could be visualized above the detection threshold of the staining. dians and interquartile ranges along with raw values for all data points ( $n$ underneath the abscissa). Solid lines represent mean rank for that treatment. c Mean intergroup differences due to Cre (i.e., mean difference between Cre+ and Cre- animals for DTR and OE, respectively) along with the probability of type 1 error and 95\% CIs for rank-transformed data.

Online supplementary Figure 2 depicts nontransformed data in addition to associated $p$ values for Shapiro-Wilk tests and probabilities of type 1 error for $\mathrm{MePD}-\mathrm{AVP}+$ neurons. One of the 4 experimental groups exhibited nonnormal distribution; thus, nonparametric statistics was used to compare intergroup differences. Expression of DTR significantly reduced and AVP overexpression increased the frequency of MePD-AVP+ neurons, congruent with rank-transformed analysis depicted in the preceding paragraphs. Infusion of DTR within MePD did not significantly alter the number of AVP+ neurons in the paraventricular nucleus of the hypothalamus ( $\left.t_{14}=0.7, p=0.497 ; \Delta \overline{\mathrm{x}}=2.8 \pm 4.0 \%\right)$, demonstrating that the effects were restricted to the effects of viral vector specific to the infusion site and did not generalize to other sites with endogenous AVP expression. 


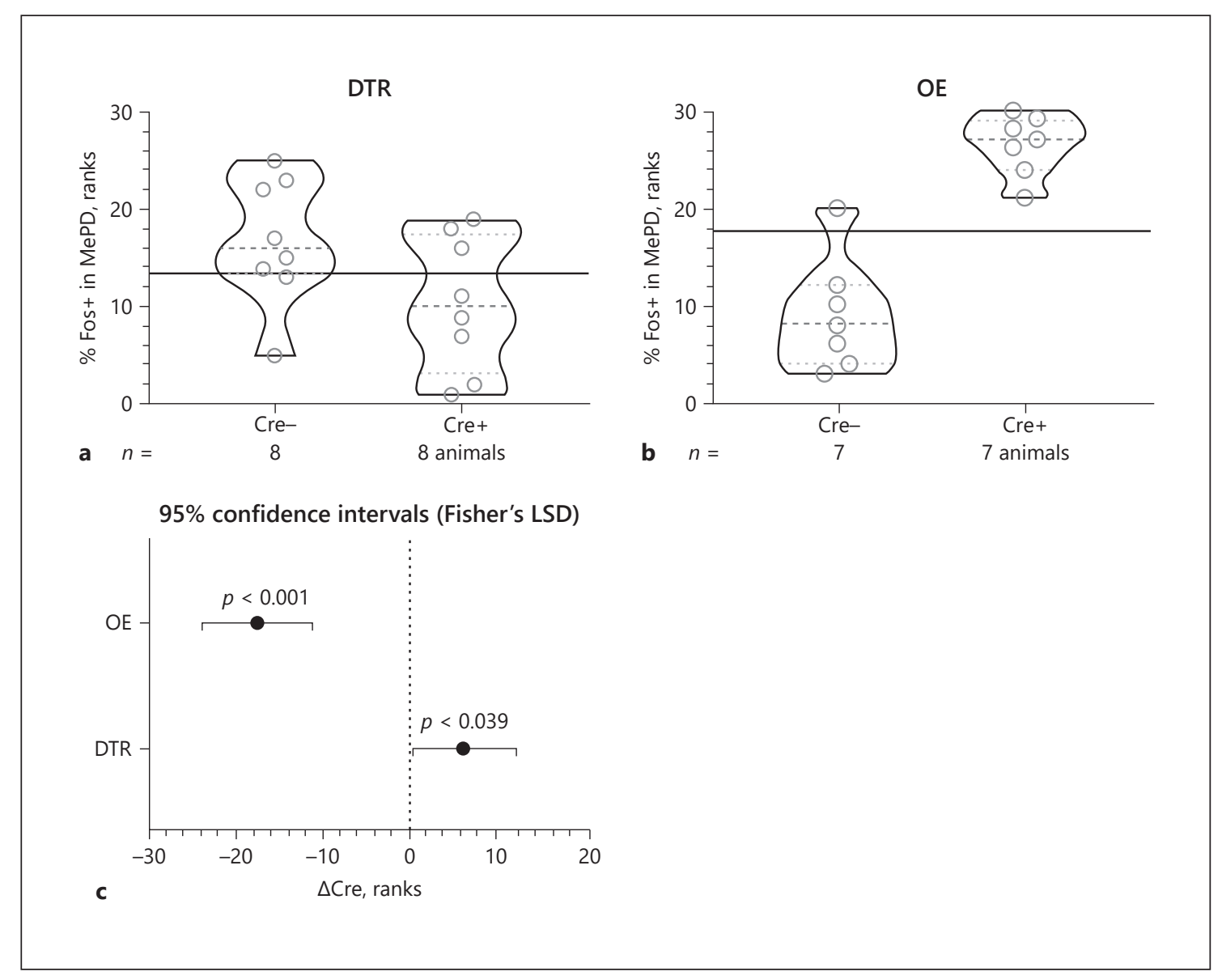

Fig. 3. Effects of experimental manipulations on posterodorsal medial amygdala (MePD) neurons showing a marker for recent neuronal activity during cat odor exposure (Fos). Data are presented for partial ablation using diphtheria toxin receptor (DTR; a) or overexpression (OE; $\mathbf{b})$. The number of Fos-positive neurons relative to total neurons counted is depicted on the ordinate after rank transformation. Violin plots in these panels depict medians and interquartile ranges along with raw values for all data points ( $n$ underneath the abscissa). Solid lines represent mean rank for that treatment. c Mean intergroup differences due to Cre (i.e., mean difference between Cre+ and Cre- animals for DTR and OE, respectively) along with the probability of type 1 error and 95\% CIs for rank-transformed data.

\section{Change in MePD AVP+ Neurons Altered Recent Neuronal Activity in Response to Cat Odor}

The presence of the intranuclear product of immediate-early gene cFos was used as a proxy for recent neuronal activity. Animals were exposed to cat urine, and recent neuronal activity was later inferred by counting Fos+ MePD neurons normalized to the total number of neurons imaged. ANOVA was conducted using rank-transformed data (Fig. 3; 2 between-subject sources of variance: DTR or OE, and Cre+ or Cre-). ANOVA revealed statistically significant interaction between vectors and Cre genotype $\left(F_{[1,26]}=30.8, p<0.001\right)$. The interaction accounted for $47 \%$ of the total variance in the design $(\Delta \overline{\mathrm{x}}=23.8 \pm 8.8$ ranks $)$. The main effect of vectors was not significant $\left(F_{[1,26]}=3.7 p=0.064\right)$. The main effect of Cre genotypes was significant $\left(F_{[1,26]}=6.6, p=0.016\right)$.

Expression of DTR in AVP+ neurons resulted in significant reduction in immunohistologically revealed MePD Fos+ neurons compared to respective Cre- controls $\left(t_{26}=2.2, p=0.039 ; \Delta \overline{\mathrm{x}}=6.4 \pm 2.9\right.$ ranks $)$. The number of Fos+ neurons in all except 1 non-DTR animal was higher than the median of DTR animals (Hedges' $g=1.0$ ). A more robust response was found when comparing $\mathrm{OE}$ animals with respective controls. Overexpression of AVP elicited a large increase in Fos+ neuron $\left(t_{26}=5.6, p<\right.$ $0.001 ; \Delta \overline{\mathrm{x}}=17.4 \pm 3.1$ ranks). All animals in the $\mathrm{OE}$ groups exhibited a greater number of Fos+ neurons than non-OE Cre-controls (Hedges' $g=3.4$ ). 


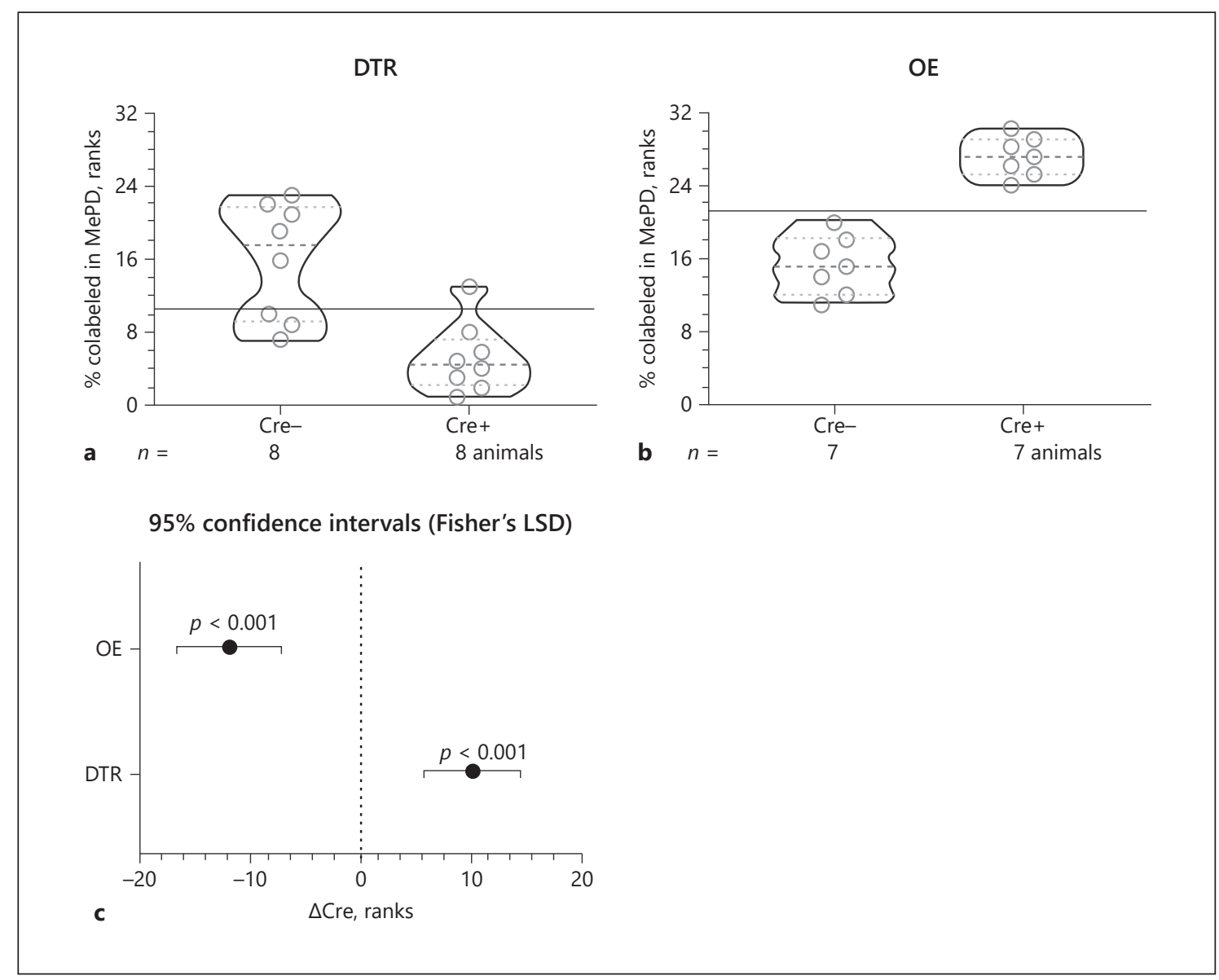

Fig. 4. Effects of experimental manipulations on posterodorsal medial amygdala (MePD) neurons colabeled with AVP and Fos in response to cat odor exposure. Data are presented for partial ablation using diphtheria toxin receptor (DTR; a) or overexpression $(\mathrm{OE} ; \mathbf{b})$. The number of colabeled neurons relative to total neurons counted is depicted on the ordinate after rank transformation. Vio-

Online supplementary Figure 3 depicts nontransformed data in addition to associated $p$ values for ShapiroWilk tests and probabilities of type 1 error for MePD-Fos+ neurons. None of the experimental groups exhibited statistically significant departure from normality of the distribution; thus, parametric statistics was used to compare intergroup differences. Expression of DTR significantly reduced and AVP overexpression increased the frequency of MePD-Fos+ neurons, congruent with rank-transformed analysis depicted in the preceding paragraphs.

\section{Ablation and Overexpression of AVP Divergently}

Affected the Recruitment of MePD-AVP+ Neurons

We further quantified the number of cells showing the colabeling of AVP and Fos. A two-way ANOVA was con- lin plots in these panels depict medians and interquartile ranges along with raw values for all data points ( $n$ underneath the abscissa). Solid lines represent mean rank for that treatment. c Mean intergroup differences due to Cre (i.e., mean difference between Cre+ and Cre- animals for DTR and OE, respectively) along with the probability of type 1 error and $95 \%$ CIs for rank-transformed data.

ducted using rank-transformed data (Fig. 4). ANOVA revealed statistically significant interaction between vectors and Cre genotype $\left(F_{[1,26]}=50.5, p<0.001\right)$. The interaction accounted for $41 \%$ of the total variance in the design $(\Delta \overline{\mathrm{x}}=22.3 \pm 6.5$ ranks). The main effect of vectors was significant $\left(F_{[1,26]}=45.3, p<0.001\right)$. The main effect of Cre genotypes was not significant $\left(F_{[1,26]}=0.1, p=0.732\right)$.

Expression of DTR in AVP+ neurons resulted in a large reduction in colabeled MePD neurons in Cre+ animals compared to respective controls $\left(t_{26}=4.9, p<0.001\right.$; $\Delta \overline{\mathrm{x}}=10.6 \pm 2.1 \mathrm{ranks})$. The number of colabeled neurons in all DTR-Cre- animals was higher than the median of DTR-Cre+ animals (Hedges' $g=1.9$ ). Congruently, overexpression of AVP elicited a huge increase in colabeled MePD neurons ( $t_{26}=5.1, p<0.001 ; \Delta \overline{\mathrm{x}}=11.7 \pm 2.3$ ranks). 


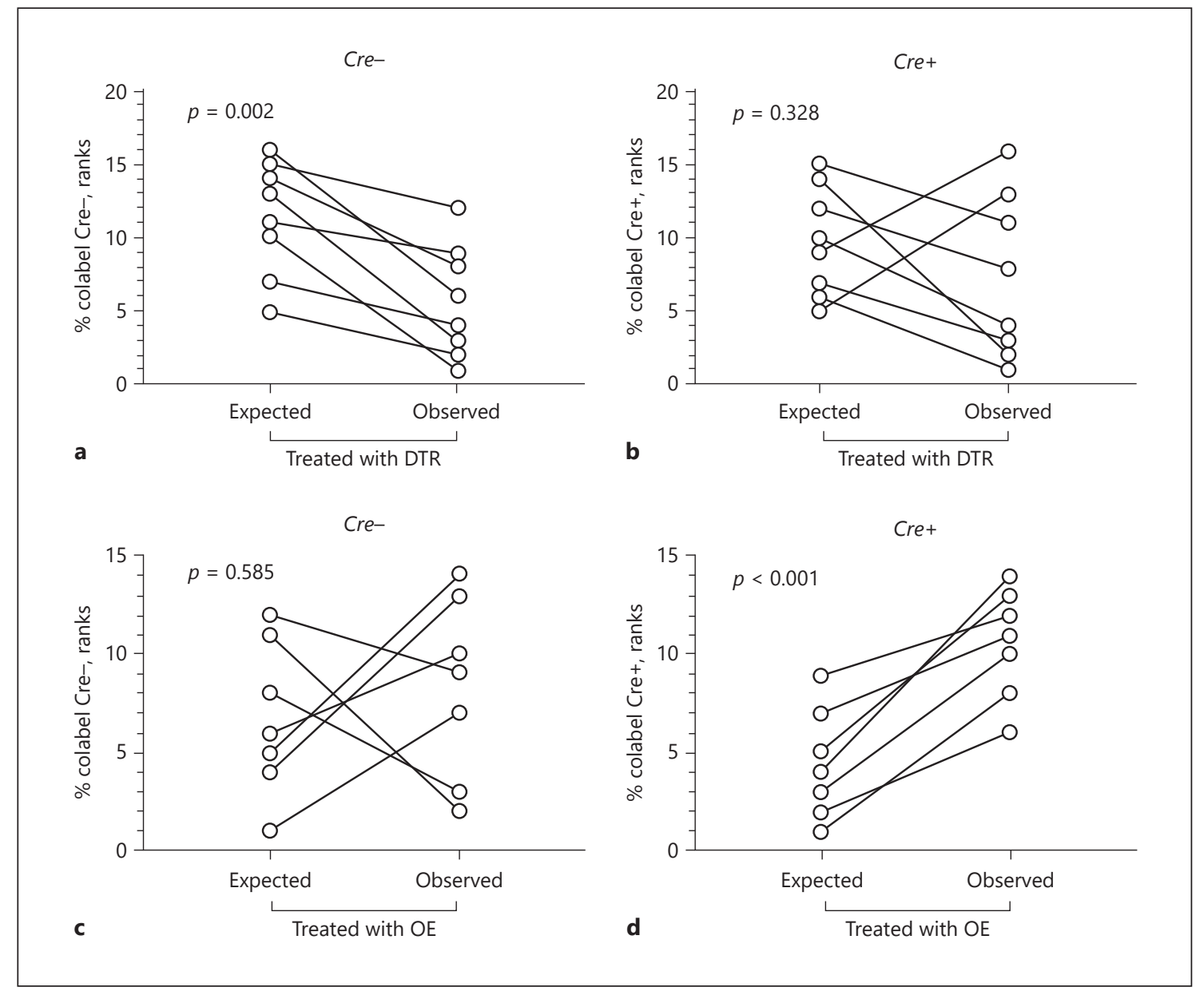

Fig. 5. Stochastic expectation and observed frequency of colabeled neurons across experimental groups. Data are presented for partial ablation using diphtheria toxin receptor (DTR; a, b) or overexpression (OE; c, d) for animals without $(\mathbf{a}, \mathbf{c})$ or with Cre $(\mathbf{b}, \mathbf{d})$. Expected and observed frequencies for individual animals are depicted using interconnected lines.

All animals in the OE groups exhibited a greater number of colabeled neurons than non-OE controls (Hedges' $g=$ 4.0).

Online supplementary Figure 4 depicts nontransformed data in addition to associated $p$ values for Shapiro-Wilk tests and probabilities of type 1 error for colabeled neurons. None of the experimental groups exhibited statistically significant departure from normality of the distribution; thus, parametric statistics was used to compare intergroup differences. Expression of DTR significantly reduced and AVP overexpression increased the frequency of colabeled neurons, congruent with ranktransformed analysis depicted in the preceding paragraphs.

Effects of AVP overexpression were especially robust when compared to partial ablation. For example, more than a third of AVP+ neurons $(35.3 \pm 3.1 \%)$ exhibited colabeled Fos expression in the $\mathrm{OE}$ group compared to $11.5 \%( \pm 1.8) \mathrm{AVP}+$ neurons in the respective controls (Student $t$ test; $t_{12}=6.61, p<0.001$ ). Similar comparison for DTR-Cre+ and respective control animals was not statistically significant $\left(t_{14}=0.51, p=0.619\right)$.

To analyze if the number of colabeled neurons was reflective of the stochastic chance of encountering a Fos+ and AVP+ neuron, we calculated the expected frequency of colabeling for each animal as the mathematical product of AVP and Fos frequencies. Expected and observed frequencies for each experimental group were rank transformed. The expected frequency was then compared to the observed frequency of colabeling using paired $t$ test (Fig. 5). Animals in the OE-Cre+ group exhibited colabeling that was significantly higher than the 


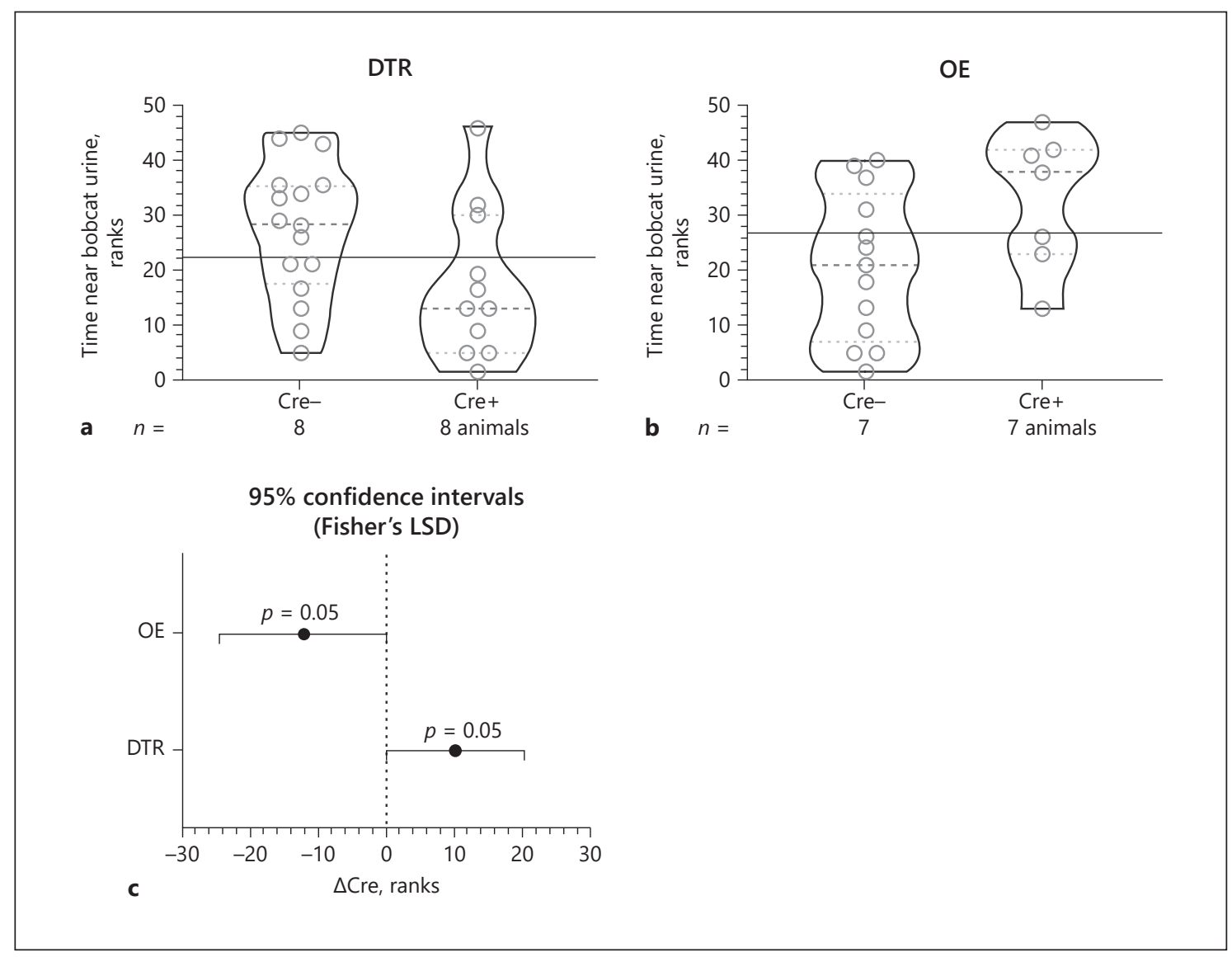

Fig. 6. Effects of experimental manipulations on the aversion to predator odor. Data are presented for partial ablation using diphtheria toxin receptor (DTR; a) or overexpression (OE; b). Time spent in the vicinity of bobcat urine is depicted on the ordinate after rank transformation. Violin plots in these panels depict me- dians and interquartile ranges along with raw values for all data points ( $n$ underneath the abscissa). Solid lines represent mean rank for that treatment. c Mean intergroup difference for DTR and OE along with the probability of type 1 error and 95\% CIs for ranktransformed data. stochastic expectation $\left(t_{6}=6.39, p<0.001\right)$. In contrast, the difference between expected and observed colabeling frequencies was not different in OE-Cre- animals $\left(t_{6}=\right.$ $0.58, p>0.58)$. This pattern was reversed during the analysis of DTR-Cre- and DTR-Cre+ animals. Observed frequency in DTR-Cre- animals was significantly lower than probabilistic expectation $\left(t_{7}=4.71, p=0.002\right)$. Animals in DTR-Cre+ animals did not exhibit significant departure between observed and expected frequencies $\left(t_{7}=1.05, p>0.30\right)$.

Online supplementary Figure 5 depicts non transformed data in addition to associated $p$ values for Shapiro-Wilk tests and probabilities of type 1 error for expected and observed frequencies. None of the observed or expected frequencies across 4 experimental groups departed from a normal distribution in a statistically significant manner. Thus, parametric statistics was used to compare intergroup differences, leading to observations congruent with rank-transformed analysis depicted in the preceding paragraphs.

\section{Change in MePD AVP+ Neurons Altered Innate Aversion to a Predator Odor}

A nonparametric test revealed that animals in both experimental groups treated with DTR vector (Cre+ and Cre-) showed a significant aversion to bobcat urine (Wilcoxon signed rank test, against the theoretical median of $600 \mathrm{~s} ; p \leq 0.001$; median $=70 \mathrm{~s}$ for DTR-Cre- and $20 \mathrm{~s}$ for DTR-Cre+). Animals in the OE-Cre- group showed a significant aversion to bobcat urine (Wilcoxon signed rank test, against the theoretical median of $600 \mathrm{~s}$; $p<0.001$; median $=40 \mathrm{~s}$ ). In contrast, animals in the OE-Cre+ group did not show statistically significant aversion to bobcat urine $(p=0.078$; median $=248 \mathrm{~s})$. 


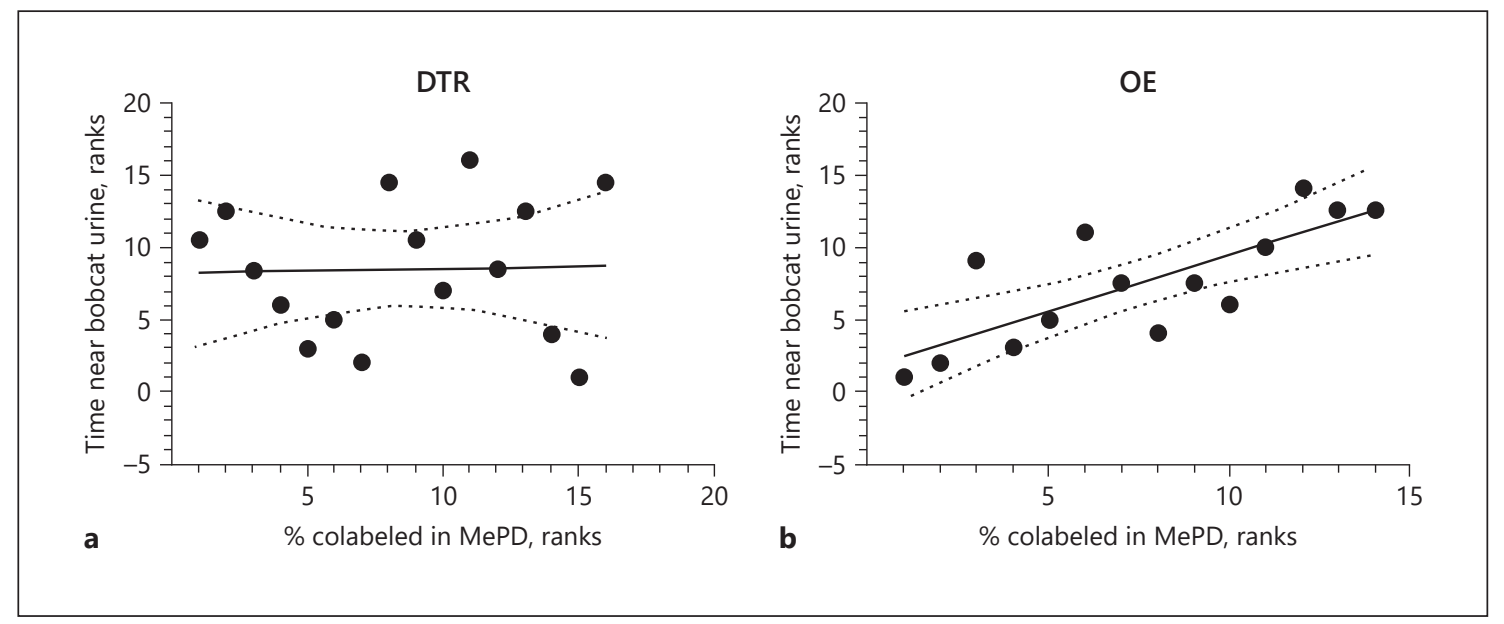

Fig. 7. Correlation between the percentage of posterodorsal medial amygdala neurons colabeled with arginine vasopressin and Fos and time spent near cat odor. Rank-transformed data were used. A linear regression trend along with 95\% CI bounds is also depicted.

We measured innate aversion by quantifying time spent by animals near bobcat urine placed in the terminus of a rectangular arena. Two-way ANOVA (Fig. 6) revealed statistically significant interaction between vectors and Cre genotype $\left(F_{[1,43]}=7.9, p=0.007\right)$. The interaction accounted for $15 \%$ of the total variance in the design $(\Delta \overline{\mathrm{x}}=22.3 \pm 16$ ranks). The main effect of vectors was not significant $\left(F_{[1,43]}=0.1, p=803\right)$. The main effect of Cre genotypes was not significant $\left(F_{[1,43]}=1.3, p=0.268\right)$.

Expression of DTR in AVP+ neurons resulted in a large reduction in time spent near predator odor in Cre+ animals compared to respective controls $\left(t_{43}=2.0, p=\right.$ $0.05 ; \Delta \overline{\mathrm{x}}=10.1 \pm 5.1$ ranks). Ranks for all except 3 DTRCre- animals were higher than the mean of all DTR-Cre+ animals (Hedges' $g=0.8$ ). Congruently, overexpression of AVP elicited a huge decrease in aversion to bobcat odor $\left(t_{43}=2.0, p=0.05 ; \Delta \overline{\mathrm{x}}=12.1 \pm 6.1\right.$ ranks $)$. All except 1 animal in the OE-Cre+ group exhibited ranks higher than the mean of corresponding OE-Cre- controls (Hedges' $g=0.9)$.

Online supplementary Figure 6 depicts nontransformed data in addition to associated $p$ values for Shapiro-Wilk tests and probabilities of type 1 error for time spent near predator odor. Three out of 4 experimental groups exhibited statistically significant departure from normal distribution; thus, nonparametric statistics was used to compare intergroup differences. Expression of DTR significantly decreased and AVP overexpression increased time spent near predator odor, congruent with rank-transformed analysis depicted in the preceding paragraphs.

MePD-AVP Neurons Regulate Innate Aversion to Cat Odors
Amount of time spent near bobcat odor by OE-Creand OE-Cre+ animals was positively correlated with the frequency of colabeled MePD neurons (Fig. 7; Spearman $r=0.77,95 \%$ confidence interval $=0.39-0.93 ; p=0.002$; $14 \mathrm{XY}$ pairs). Such correlation was absent in DTR-Creand DTR-Cre+ animals (Spearman $r=0.04,95 \%$ confidence interval $=-0.48$ to $0.53 ; p=0.897 ; 16 \mathrm{XY}$ pairs $)$.

\section{Discussion}

Results in this report suggest that MePD-AVP+ neurons inversely regulate defensive response to a predator odor. Experimental manipulation that raises the amount of AVP within MePD-AVP+ neurons leads to preferential recruitment of these neurons during cat odor exposure and reflects lower aversion. The preferential recruitment in this case is evidenced by the extent of colabeling that surpasses the probabilities calculated based on random chance and on individual frequencies of AVP and Fos-labeled cells. Congruently, experimentally achieved partial ablation of MePD-AVP+ neurons causes greater aversion to cat odors. We will first contextualize the numerical magnitude of these observations. We will then interpret these results in light of known functions of the $\mathrm{MePD}$ and male gonadal hormones. We will then provide some testable hypotheses to further confirm or reject our interpretation.

Table 1 summarizes effect sizes observed in the present experiments along with corresponding probabilities of type 1 error. There are 2 principal ways to contextualize 
the magnitude of these effect sizes. The first avenue is the conventional frame of reference that defines effect sizes $>0.8$ as being "large" [52]. At this arbitrary number, 79\% of the treated population is expected to reside above the mean of the control population, and there is $\sim 71 \%$ chance that an animal picked at random from the treated group will have a higher rank than an animal picked at random from the corresponding control group. All reported effects in Table 1 either meet or exceed this conventional criterion for the large effect size. The second avenue is to compare the effect size with prior reports that examine the same neuronal population or the same behavioral phenotype. MePD-AVP+ neurons were earlier reported to be preferentially recruited during exposure to the odor of estrus females in rats [37]. The estimated effect size for this effect is $\approx 2.2$, which compares very well with $g$ of 4.0 or 1.9 observed in the present report for overexpression and ablation, respectively. Interestingly, the effect we observe in response to AVP overexpression is quantitatively large and in the same direction as expected in response to sexual experiences rather than cat odor exposure being used in the experiment. Similarly, infection with the protozoan parasite Toxoplasma gondii is known to cause a reduction in aversion to predator odor similar to the effects of AVP overexpression observed in this report [53]. The effect sizes for these experiments are estimated to be 0.7 [53], which again compares favorably with $g$ of $0.7-0.8$ observed for the behavioral effects in this report. Thus, partial ablation of MePD-AVP+ neurons robustly increases innate aversion to cat odor. Similarly, AVP overexpression in the same neuronal population robustly decreases innate aversion and congruently causes markedly increased recruitment of MePD-AVP+ neurons in response to cat odor exposure.

We did not measure sociosexual behaviors per se in the present report. Yet, multiple strands of evidence suggest that MePD-AVP+ neurons are involved in male sexual behaviors, especially the appetitive aspects of reproduction. Adult male rats have a MePD that is almost double the volume of the female nucleus [54]. Sexual dimorphism in MePD is similar to the bed nucleus of the stria terminalis, an analogous structure within the medial aspect of the extended amygdala. Such sexual dimorphism requires the continual presence of testosterone because castration renormalizes male MePD volume to the level seen in females, and exogenous testosterone supplement reinstates the volume to the precastration level [32]. Similarly, castrated animals no longer exhibit the presence of AVP-containing axons projecting from the MePD and bed nucleus of stria terminalis, while testosterone supple- mentation reinstates AVP in these efferents [55]. In rats, testosterone creates an epigenetic change within the bed nucleus of stria terminalis in the form of DNA hypomethylation on the AVP promotor [33]. Similarly, AVP promotor in mice MePD undergoes DNA hypomethylation in response to testosterone [56]. These observations provide a molecular link between male gonadal hormones and ongoing plasticity in adult MePD-AVP+ neurons. Placement of testosterone within MePD reconstitutes sexual motivation in castrated animals $[2,57]$, further supporting the notion that testosterone effects of male sexual behavior requires intact MePD.

$\mathrm{MePD}-\mathrm{AVP}+$ efferents project to brain regions that are involved in the regulation of motivational states [13, 15]. For example, AVP+ fibers from the MePD and bed nucleus of stria terminalis are found in the lateral septum, an essential regulator of the mesolimbic dopamine system [17]. The functional significance of AVP projections within the lateral septum is supported by observations that infusion of AVP within this brain region rescues progesterone-induced impairment of social recognition in male rats $[14,58]$. These fibers are also seen in the ventral pallidum, a part of the mesolimbic system, where antagonism of the AVP receptor reduces sociosexual behaviors [19]. Thus, MePD-AVP+ neurons have appropriate axonal projections that can reliably alter male-specific behaviors.

Castrated male mice show less innate aversion to bobcat odors when they are supplemented with exogenous testosterone [55]. It is likely that the effects of testosterone on fear flows through its effects on MePD-AVP+ neurons. This is supported by the observation that experimentally creating DNA hypomethylation within rat $\mathrm{MePD}$, akin to the effects exerted by testosterone, reduces defensive behaviors [59]. Individual rats that show proactive investigatory forays towards cat fur also show concomitant DNA hypomethylation of AVP promotor within MePD [60]. These observations suggest that testosterone-responsive MePD-AVP plasticity has behavioral consequences for defensive behaviors apart from the better-studied role of this neuronal population in male-specific reproduction. In this report, experimental treatment that increased recruitment of MePD-AVP+ neurons reduced innate aversion to cat odor, and treatment that reduced the total amount of MePD-AVP+ neurons increased aversion to cat odor. Cat odors are believed to be processed primarily by the posteroventral medial amygdala $[20,21,61]$. Ablation of this subnucleus, for example, reduces aversion to cat odors [27]. In contrast, MePD is thought to be involved in sociosexual 
behaviors. The data in the present report suggest that the dichotomy between posteroventral and posterodorsal aspects of the medial amygdala is, in fact, not absolute. While neuronal activity within the posteroventral medial amygdala is needed for defensive behaviors, neuronal activity within the MePD suppresses aversion to predator cues.

The present observations suggest that increasing the amount of AVP in MePD neurons that endogenously express AVP results in an increase in the activation of these neurons upon predator odor exposure. AVP in the brain binds to both its canonical receptor (AVP1aR) and oxytocin receptor (OXTR) [62]. AVP and oxytocin contain 7 similar out of 9 constituent amino acids. AVP1aR and OXTR, similarly, show high sequence homology [63], with AVP exhibiting the same binding affinity to both of these receptors [62]. The effects of AVP on rodent social behaviors involve both AVP1aR and OXTR [64]. Thus, the effects of AVP overexpression or ablation can flow from brain regions that express either of these 2 receptors $[65,66]$. In adult mice, the posterior medial amygdala contains copious amounts of AVP-immunoreactive fibers $[13,17,67]$ but sparse AVP1aR density $[68,69]$. This brain region also shows low numbers of oxytocin-containing fibers in male mice, with dense OXTR distribution [70-72]. Furthermore, castration simultaneously reduces the amount of AVP transcription [56] and OXTR binding density [73] within the medial amygdala, while leaving hypothalamic sources of the AVP intact. These observations suggest that the effects of AVP in MePD might result from the interaction of AVP-containing axons and OXTR present in the vicinity.

An interesting corollary to the present observation can also be found during infection of rats by the protozoan parasite T. gondii. The complex life cycle of this parasite requires the predation of chronically infected animals by cats in order for its gametogenesis [74]. Several experiments have shown that $T$. gondii infection reduced the innate aversion of infected rats to cat odors $[53,75]$. This likely increases predation rates and hence transmission of the parasite; however, direct evidence of increased predation is lacking. What is interesting in the present backdrop is the mechanism by which innate aversion is reduced. Infected animals show higher transcription of AVP within MePD [59]. In addition, MePD-AVP+ neurons in the infected animals show evidence of recent neuronal activity when rats are exposed to cat odor [59] in parallel to a greater than expected chance of colabeling between AVP and immediate-early gene markers of recent activity. This phenomenon is concomitant with in-

MePD-AVP Neurons Regulate Innate

Aversion to Cat Odors creased testosterone production in the infected rats [76] and establishment of behaviors that are testosterone dependent $[77,78]$ - thus stressing the underlying role of interactions between testosterone, the MePD-AVP+ system, and its efferents in the regulation of defensive behaviors. While the T. gondii model points towards a possibility that MePD-AVP+ neurons might be involved in the reduction of defensive behavior towards predators, this model stops short of tearing apart the causal aspects. It is not possible to separate out a host of inflammatory and neural changes that co-occur during a chronic infection. Present observations go one step further from correlations described in the T. gondii model and show that an experimental increase in MePD-AVP is sufficient to reduce innate aversion.

The emerging narrative then is that MePD-AVP neurons inversely titrate defense to predation in addition to engaging in sociosexual behaviors. Imperatives of sex and defense are typically contrary to each other [2-7]. Maximal defense from predators precludes investment in sexual advertisements and sexual pursuits. Thus, it is plausible that behaviors that underpin sexual behavior could be syndromic with the reduction in antipredator behaviors. Reproduction could be favored over the defense in ecologies where payoff from current reproduction outweighs opportunity costs in terms of survival and residual reproduction [79-82]. We posit that the MePD-AVP system is a proximate link in the negotiation of such conditional calibration of defense in the face of current reproduction. The medial amygdala is the first site of convergence for olfactory information from the main and accessory olfactory system. This suggests that the medial amygdala has access to information about the availability of sexual opportunities in the external environment $[10,11]$. The medial amygdala, specifically AVP neurons within MePD, is also responsive to testosterone and its metabolites [2, 15, 28, 30-33]. This responsiveness takes the form of DNA hypomethylation in the AVP promoter [33]. This epigenetic change provides the medial amygdala further information about the internal metabolic milieu and the possibility of a metabolic reserve that would be presumably needed for investment in sexual pursuits. The confluence of information about external and internal cues pertaining to the possibility of current reproduction might allow MePD-AVP neurons to initiate a behavioral sequela characterized by reduced defense and increased reproduction. In other words, the MePD-AVP system acts as an arbitrator for the trade-off between current and residual reproduction in male mice.

Neuroendocrinology 2021;111:505-520 DOI: $10.1159 / 000508862$ 
We provide a proximate justification for the hypothesis described in the previous paragraph. Partial ablation of the MePD-AVP system increased fear of cat odors, and MePD-AVP overexpression reduced the same fear. This leads to at least 2 testable predictions for future experiments. If MePD-AVP is involved in trade-offs between current and residual reproduction, then the manipulation of this system should not change defense response to predators where such a trade-off is not ecologically relevant. This can be tested, firstly, by comparing a semelparous species with phylogenetically related iteroparous species. Our hypothesis will be supported if overexpression of AVP (or its analogous peptide, vasotocin, in birds) reduces defensive behavior in the iteroparous but not semelparous counterpart. It can also be tested, secondly, by comparing a monogamous species with reduced sexual selection with phylogenetically related polygynandrous species. Our hypothesis will be supported if overexpression of MePD-AVP leads to loss of defensive behaviors in polygynandrous species but not the monogamous counterpart.

In conclusion, we provide evidence that experimental manipulation of a nonapeptide neuronal population, known to have a role in sexual behaviors, can concomitantly regulate innate aversion to predator cues in mice. We posit that this phenomenon reflects trade-offs inherent in investments between sexual reproduction and defense.

\section{Acknowledgment}

We thank George Augustine for the gift of the mouse strain. We thank Albert Chen and Ayumu Tashiro for the contribution of molecular reagents.

\section{Statement of Ethics}

All experimental procedures were reviewed and approved by the Institutional Animal Care and Use Committee of the Nanyang Technological University.

\section{Conflict of Interest Statement}

Authors declare the absence of any competing interests.

\section{Funding Sources}

This work was financially supported by the Human Frontier Science Program (grant RGP0062/2018).

\section{Author Contributions}

W.H.T. carried out the experiments, performed the data analysis, and prepared the manuscript; S.A.-S. carried out the experiments; A.V. performed the data analysis, conceived the idea, supervised the research, and prepared the manuscript. All authors approved the final manuscript.

\section{References}

1 O'Connell LA, Hofmann HA. Genes, hormones, and circuits: an integrative approach to study the evolution of social behavior. Front Neuroendocrinol. 2011 Aug;32(3): 320-35.

2 Bialy M, Sachs BD. Androgen implants in medial amygdala briefly maintain noncontact erection in castrated male rats. Horm Behav. 2002 Nov;42(3):345-55.

3 Wingfield JC, Sapolsky RM. Reproduction and resistance to stress: when and how. J Neuroendocrinol. 2003 Aug;15(8):711-24.

4 Fuelling O, Halle S. Breeding suppression in free-ranging grey-sided voles under the influence of predator odour. Oecologia. 2004 Jan; 138(1):151-9.

5 Zanette L, Clinchy M, Smith JN. Food and predators affect egg production in song sparrows. Ecology. 2006 Oct;87(10):2459-67.

6 Zanette LY, White AF, Allen MC, Clinchy M. Perceived predation risk reduces the number of offspring songbirds produce per year. Science. 2011 Dec;334(6061):1398-401.
7 Ferkin MH. Odor communication and mate choice in rodents. Biology (Basel). 2018 Jan; $7(1): 7$.

8 Newman SW. The medial extended amygdala in male reproductive behavior. A node in the mammalian social behavior network. Ann N Y Acad Sci. 1999 Jun 29;877:242-57.

9 O'Connell LA, Hofmann HA. The vertebrate mesolimbic reward system and social behavior network: a comparative synthesis. J Comp Neurol. 2011 Dec;519(18):3599-639.

10 Brennan PA, Zufall F. Pheromonal communication in vertebrates. Nature. 2006 Nov; 444(7117):308-15.

11 Guthman EM, Vera J. A cellular mechanism for main and accessory olfactory integration at the medial amygdala. J Neurosci. 2016 Feb; 36(7):2083-5.

12 Dorsa DM, Petracca FM, Baskin DG, Cornett LE. Localization and characterization of vasopressin-binding sites in the amygdala of the rat brain. J Neurosci. 1984 Jul;4(7):1764-70.
13 Rood BD, De Vries GJ. Vasopressin innervation of the mouse (Mus musculus) brain and spinal cord. J Comp Neurol. 2011 Aug; 519(12):2434-74.

14 Bychowski ME, Mena JD, Auger CJ. Vasopressin infusion into the lateral septum of adult male rats rescues progesterone-induced impairment in social recognition. Neuroscience. 2013 Aug;246:52-8.

15 Rood BD, Stott RT, You S, Smith CJ, Woodbury ME, De Vries GJ. Site of origin of and sex differences in the vasopressin innervation of the mouse (Mus musculus) brain. J Comp Neurol. 2013 Jul;521(10):2321-58.

16 Rood BD, Beck SG. Vasopressin indirectly excites dorsal raphe serotonin neurons through activation of the vasopressin $1 \mathrm{~A}$ receptor. Neuroscience. 2014 Feb;260:205-16.

17 DiBenedictis BT, Nussbaum ER, Cheung HK, Veenema AH. Quantitative mapping reveals age and sex differences in vasopressin, but not oxytocin, immunoreactivity in the rat social behavior neural network. J Comp Neurol. 2017 Aug;525(11):2549-70. 
18 Smith CJ, DiBenedictis BT, Veenema AH. Comparing vasopressin and oxytocin fiber and receptor density patterns in the social behavior neural network: implications for crosssystem signaling. Front Neuroendocrinol. 2019 Apr;53:100737.

19 DiBenedictis BT, Cheung HK, Nussbaum ER, Veenema AH. Involvement of ventral pallidal vasopressin in the sex-specific regulation of sociosexual motivation in rats. Psychoneuroendocrinology. 2020 Jan;111:104462.

20 Dielenberg RA, Hunt GE, McGregor IS. "When a rat smells a cat": the distribution of Fos immunoreactivity in rat brain following exposure to a predatory odor. Neuroscience. 2001;104(4):1085-97.

21 Canteras NS. The medial hypothalamic defensive system: hodological organization and functional implications. Pharmacol Biochem Behav. 2002 Mar;71(3):481-91.

22 Meredith M, Westberry JM. Distinctive responses in the medial amygdala to same-species and different-species pheromones. J Neurosci. 2004 Jun;24(25):5719-25.

23 Choi GB, Dong HW, Murphy AJ, Valenzuela DM, Yancopoulos GD, Swanson LW, et al. Lhx6 delineates a pathway mediating innate reproductive behaviors from the amygdala to the hypothalamus. Neuron. 2005 May;46(4): 647-60.

24 Maras PM, Petrulis A. Chemosensory and steroid-responsive regions of the medial amygdala regulate distinct aspects of opposite-sex odor preference in male Syrian hamsters. Eur J Neurosci. 2006 Dec;24(12):354152.

25 Goodson JL, Kabelik D. Dynamic limbic networks and social diversity in vertebrates: from neural context to neuromodulatory patterning. Front Neuroendocrinol. 2009 Oct;30(4): 429-41.

26 Kondo Y. Lesions of the medial amygdala produce severe impairment of copulatory behavior in sexually inexperienced male rats. Physiol Behav. 1992 May;51(5):939-43.

27 Blanchard DC, Canteras NS, Markham CM, Pentkowski NS, Blanchard RJ. Lesions of structures showing FOS expression to cat presentation: effects on responsivity to a cat, cat odor, and nonpredator threat. Neurosci Biobehav Rev. 2005;29(8):1243-53.

28 Wang Z, Bullock NA, De Vries GJ. Sexual differentiation of vasopressin projections of the bed nucleus of the stria terminals and medial amygdaloid nucleus in rats. Endocrinology. 1993 Jun;132(6):2299-306.

29 Ferris CF, Delville Y, Miller MA, Dorsa DM, De Vries GJ. Distribution of small vasopressinergic neurons in golden hamsters. J Comp Neurol. 1995 Oct;360(4):589-98.

30 Wang Z, De Vries GJ. Androgen and estrogen effects on vasopressin messenger RNA expression in the medial amygdaloid nucleus in male and female rats. J Neuroendocrinol. 1995 Nov;7(11):827-31.
31 Mizukami S, Nishizuka M, Arai Y. Sexual difference in nuclear volume and its ontogeny in the rat amygdala. Exp Neurol. 1983 Feb;79(2): 569-75.

32 Cooke BM. Steroid-dependent plasticity in the medial amygdala. Neuroscience. 2006; 138(3):997-1005.

33 Auger CJ, Coss D, Auger AP, Forbes-Lorman RM. Epigenetic control of vasopressin expression is maintained by steroid hormones in the adult male rat brain. Proc Natl Acad Sci USA. 2011 Mar; 108(10):4242-7.

34 Aste N, Honda S, Harada N. Forebrain Fos responses to reproductively related chemosensory cues in aromatase knockout mice. Brain Res Bull. 2003 May;60(3):191-200.

35 Morris JA, Jordan CL, King ZA, Northcutt KV, Breedlove SM. Sexual dimorphism and steroid responsiveness of the posterodorsal medial amygdala in adult mice. Brain Res. 2008 Jan;1190:115-21.

36 Ho JM, Murray JH, Demas GE, Goodson JL. Vasopressin cell groups exhibit strongly divergent responses to copulation and malemale interactions in mice. Horm Behav. 2010 Aug;58(3):368-77.

37 Hari Dass SA, Vyas A. Copulation or sensory cues from the female augment Fos expression in arginine vasopressin neurons of the posterodorsal medial amygdala of male rats. Front Zool. 2014 Jun;11(1):42.

$38 \mathrm{He} \mathrm{F,} \mathrm{Wu} \mathrm{R,} \mathrm{Yu} \mathrm{P.} \mathrm{Study} \mathrm{of} \mathrm{Fos,} \mathrm{androgen} \mathrm{re-}$ ceptor and testosterone expression in the subregions of medial amygdala, bed nucleus of stria terminalis and medial preoptic area in male Mandarin voles in response to chemosensory stimulation. Behav Brain Res. 2014 Jan;258:65-74.

39 Kabelik D, Morrison JA, Goodson JL. Cryptic regulation of vasotocin neuronal activity but not anatomy by sex steroids and social stimuli in opportunistic desert finches. Brain Behav Evol. 2010;75(1):71-84.

40 Goodson JL, Kelly AM, Kingsbury MA. Evolving nonapeptide mechanisms of gregariousness and social diversity in birds. Horm Behav. 2012 Mar;61(3):239-50.

41 Kelly AM, Goodson JL. Behavioral relevance of species-specific vasotocin anatomy in gregarious finches. Front Neurosci. 2013 Dec;7:242.

42 Kelly AM, Goodson JL. Functional significance of a phylogenetically widespread sexual dimorphism in vasotocin/vasopressin production. Horm Behav. 2013 Nov;64(5):840-6.

43 Harris JA, Hirokawa KE, Sorensen SA, Gu H, Mills M, Ng LL, et al. Anatomical characterization of Cre driver mice for neural circuit mapping and manipulation. Front Neural Circuits. 2014 Jul;8:76.

44 Xi D, Long C, Lai M, Casella A, O’Lear L, Kublaoui B, et al. Ablation of Oxytocin Neurons Causes a Deficit in Cold Stress Response. J Endocr Soc. 2017 Jul;1(8):1041-55.
45 Jiang Z, Rajamanickam S, Justice NJ. Local Corticotropin-Releasing Factor Signaling in the Hypothalamic Paraventricular Nucleus. J Neurosci. 2018 Feb;38(8):1874-90.

46 Paxinos G, Franklin K. The mouse brain in stereotaxic coordinates. San Diego, CA: Academic Press; 2001.

47 Royston P. Remark AS R94: A remark on algorithm AS 181: The W-test for normality. J R Stat Soc Ser C Appl Stat. 1995;44:547-51.

48 Conover WJ, Iman RL. Rank transformations as a bridge between parametric and nonparametric statistics. Am Stat. 1981;35:124-9.

49 Motulsky HJ, Brown RE. Detecting outliers when fitting data with nonlinear regression a new method based on robust nonlinear regression and the false discovery rate. BMC Bioinformatics. 2006 Mar;7(1):123.

50 Ruxton GD, Beauchamp G. Time for some a priori thinking about post hoc testing. Behav Ecol. 2008;19(3):690-3.

51 Hedges LV, Olkin I. Statistical methods for meta-analysis. Academic press; 2014.

52 Cohen J. Statistical power analysis for the behavioral sciences. Routledge; 2013.

53 Berdoy M, Webster JP, Macdonald DW. Fatal attraction in rats infected with Toxoplasma gondii. Proc Biol Sci. 2000 Aug;267(1452): 1591-4.

54 Hines M, Allen LS, Gorski RA. Sex differences in subregions of the medial nucleus of the amygdala and the bed nucleus of the stria terminalis of the rat. Brain Res. 1992 May;579(2): 321-6.

55 de Vries GJ, Buijs RM, Sluiter AA. Gonadal hormone actions on the morphology of the vasopressinergic innervation of the adult rat brain. Brain Res. 1984 Apr;298(1):141-5.

56 Tong WH, Abdulai-Saiku S, Vyas A. Testosterone reduces fear and causes drastic hypomethylation of arginine vasopressin promoter in medial extended amygdala of male mice. Front Behav Neurosci. 2019 Feb;13:33.

57 Bialy M, Nikolaev-Diak A, Kalata U, Nikolaev E. Blockade of androgen receptor in the medial amygdala inhibits noncontact erections in male rats. Physiol Behav. 2011 Jun;103(34):295-301.

58 Auger CJ, Vanzo RJ. Progesterone treatment of adult male rats suppresses arginine vasopressin expression in the bed nucleus of the stria terminalis and the centromedial amygdala. J Neuroendocrinol. 2006 Mar;18(3): 187-94.

59 Hari Dass SA, Vyas A. Toxoplasma gondii infection reduces predator aversion in rats through epigenetic modulation in the host medial amygdala. Mol Ecol. 2014 Dec;23(24): 6114-22.

60 Bowen MT, Dass SA, Booth J, Suraev A, Vyas A, McGregor IS. Active coping toward predatory stress is associated with lower corticosterone and progesterone plasma levels and decreased methylation in the medial amygdala vasopressin system. Horm Behav. 2014 Aug; 66(3):561-6.
MePD-AVP Neurons Regulate Innate Aversion to Cat Odors
Neuroendocrinology 2021;111:505-520 DOI: $10.1159 / 000508862$ 
61 Pardo-Bellver C, Cádiz-Moretti B, Novejarque A, Martínez-García F, Lanuza E. Differential efferent projections of the anterior, posteroventral, and posterodorsal subdivisions of the medial amygdala in mice. Front Neuroanat. 2012 Aug;6:33.

62 Thibonnier M, Coles P, Thibonnier A, Shoham $M$. The basic and clinical pharmacology of nonpeptide vasopressin receptor antagonists. Annu Rev Pharmacol Toxicol. 2001; 41(1):175-202.

63 Koehbach J, Stockner T, Bergmayr C, Muttenthaler M, Gruber CW. Insights into the molecular evolution of oxytocin receptor ligand binding. Biochem Soc Trans. 2013 Feb; 41(1):197-204.

64 Song Z, Albers HE. Cross-talk among oxytocin and arginine-vasopressin receptors: relevance for basic and clinical studies of the brain and periphery. Front Neuroendocrinol. 2018 Oct;51:14-24.

65 Landgraf R, Neumann ID. Vasopressin and oxytocin release within the brain: a dynamic concept of multiple and variable modes of neuropeptide communication. Front Neuroendocrinol. 2004 Sep-Dec;25(3-4):150-76.

66 Albers HE. Species, sex and individual differences in the vasotocin/vasopressin system: relationship to neurochemical signaling in the social behavior neural network. Front Neuroendocrinol. 2015 Jan;36:49-71.

67 De Vries GJ, Buijs RM. The origin of the vasopressinergic and oxytocinergic innervation of the rat brain with special reference to the lateral septum. Brain Res. 1983 Aug;273(2): 307-17.
68 Lukas M, Bredewold R, Neumann ID, Veenema AH. Maternal separation interferes with developmental changes in brain vasopressin and oxytocin receptor binding in male rats. Neuropharmacology. 2010 Jan;58(1):78-87.

69 Dumais KM, Veenema AH. Vasopressin and oxytocin receptor systems in the brain: sex differences and sex-specific regulation of social behavior. Front Neuroendocrinol. 2016 Jan;40:1-23.

70 Campbell P, Ophir AG, Phelps SM. Central vasopressin and oxytocin receptor distributions in two species of singing mice. J Comp Neurol. 2009 Oct;516(4):321-33.

71 Dumais KM, Bredewold R, Mayer TE, Veenema AH. Sex differences in oxytocin receptor binding in forebrain regions: correlations with social interest in brain region- and sexspecific ways. Horm Behav. 2013 Sep;64(4): 693-701.

72 Smith CJ, Poehlmann ML, Li S, Ratnaseelan AM, Bredewold R, Veenema AH. Age and sex differences in oxytocin and vasopressin V1a receptor binding densities in the rat brain: focus on the social decision-making network. Brain Struct Funct. 2017 Mar;222(2):9811006.

73 Tribollet E, Audigier S, Dubois-Dauphin M, Dreifuss JJ. Gonadal steroids regulate oxytocin receptors but not vasopressin receptors in the brain of male and female rats. An autoradiographical study. Brain Res. 1990 Mar; 511(1):129-40.
74 Boothroyd JC. Toxoplasma gondii: 25 years and 25 major advances for the field. Int J Parasitol. 2009 Jul;39(8):935-46.

75 Vyas A. Mechanisms ofhost behavioral change in toxoplasma gondii rodent association. PLoS Pathog. 2015 Jul;11(7):e1004935.

76 Lim A, Kumar V, Hari Dass SA, Vyas A. Toxoplasma gondii infection enhances testicular steroidogenesis in rats. Mol Ecol. 2013 Jan;22(1):102-10.

77 Tan D, Soh LJ, Lim LW, Daniel TC, Zhang X, Vyas A. Infection of male rats with Toxoplasma gondii results in enhanced delay aversion and neural changes in the nucleus accumbens core. Proc Biol Sci. 2015 Jun 7;282(1808): 20150042.

78 Tan D, Vyas A. Toxoplasma gondii infection and testosterone congruently increase tolerance of male rats for risk of reward forfeiture. Horm Behav. 2016 Mar;79:37-44.

79 Magnhagen C. Predation risk as a cost of reproduction. Trends Ecol Evol. 1991 Jun;6(6): 183-6.

80 Candolin U. Reproduction under predation risk and the trade-off between current and future reproduction in the threespine stickleback. Proc R Soc Lond B Biol Sci. 1998; 265(1402):1171-5.

81 Pavlová V, Berec L, Boukal DS. Caught between two Allee effects: trade-off between reproduction and predation risk. J Theor Biol. 2010 Jun;264(3):787-98.

82 Öst M, Lindén A, Karell P, Ramula S, Kilpi M. To breed or not to breed: drivers of intermittent breeding in a seabird under increasing predation risk and male bias. Oecologia. 2018 Sep;188(1):129-38. 